\title{
Radiolanthanides Device Production
}

\author{
F. Monroy-Guzman*, F. Jimenez Barreiro, E. Jaime Salinas, A. L. Vera Treviño \\ Instituto Nacional de Investigaciones Nucleares, Ocoyoacac, Mexico \\ Email: fabiola.monroy@inin.gob.mx
}

Received 22 February 2015; accepted 24 April 2015; published 28 April 2015

Copyright (C) 2015 by authors and Scientific Research Publishing Inc.

This work is licensed under the Creative Commons Attribution International License (CC BY).

http://creativecommons.org/licenses/by/4.0/

(c) (7) Open Access

\begin{abstract}
${ }^{149} \mathrm{Pm},{ }^{166} \mathrm{Ho},{ }^{161} \mathrm{~Tb}$ and ${ }^{177} \mathrm{Lu}$ conjugated to chemical agents (monoclonal antibodies, polypeptide, etc.) have the appropriate decay characteristics for imaging and therapeutic studies and consequently the potential to be useful in radiotherapy and diagnosis. These carrier-free radioisotopes can be produced by neutron irradiation of a lanthanide target followed by $\beta^{-}$decay, and a posterior radiochemical separation of the daughter radionuclide from macro-amounts of the parent target. In order to produce carrier free ${ }^{149} \mathrm{Pm},{ }^{161} \mathrm{~Tb},{ }^{166} \mathrm{Ho}$ and ${ }^{177} \mathrm{Lu}$ for radiotherapy, with a radionuclide purity of more than $99.9 \%$, a device production was developed based on separation of $\mathrm{Nd} / \mathrm{Pm}, \mathrm{Gb} / \mathrm{Tb}, \mathrm{Dy} / \mathrm{Ho}$ and $\mathrm{Yb} / \mathrm{Lu}$ by extraction chromatography.
\end{abstract}

\section{Keywords}

${ }^{149} \mathrm{Pm},{ }^{161} \mathrm{~Tb},{ }^{166} \mathrm{Ho},{ }^{177} \mathrm{Lu}$, Production

\section{Introduction}

Targeted tumor radiotherapy uses radionuclides conjugated to chemically-guided agents such as labelled monoclonal antibodies or isotopically-labelled polypeptide. These agents require radioisotopes with high specific activity, high LET particle emissions, photon emissions for monitoring therapy with imaging and follow-up as well as adsorbed dose distribution and half-lives long enough to allow the preparation and distribution of radiopharmaceuticals [1]-[6]. High energy beta emitting radionuclides are preferentially used in these agents to kill tumoral cells [4]. Radioactive lanthanides such as ${ }^{149} \mathrm{Pm},{ }^{161} \mathrm{~Tb},{ }^{166} \mathrm{Ho}$ and ${ }^{177} \mathrm{Lu}$, have a great potential in radiotherapy because they are beta or Auger-electron emitters with just enough gammas to enable imaging, with halflives long enough to allow preparation and distribution of the radiopharmaceuticals, and can be prepared at high specific activities (carrier-free) (see Table 1).

Chemically, lanthanides $\left(\mathrm{Ln}^{3+}\right)$ have the ability to replace $\mathrm{Ca}^{2+}$ in biological systems (e.g. enzymes, proteins, cells, cytoplasm). Additionally, they could cause the inhibition of collagenase or lymphocyte activation, the sta-

\footnotetext{
${ }^{*}$ Corresponding author.
} 
Table 1. Radiolanthanides nuclear properties with use potential in radiotherapy and diagnosis.

\begin{tabular}{ccccc}
\hline Radioisotope & $\beta^{-} \max (\mathrm{MeV})$ & $\gamma$ energy $(\mathrm{KeV})$ & Half-life & \multicolumn{2}{c}{ Stable daughter } \\
\hline${ }^{149} \mathrm{Pm}$ & 1.071 & $285.9(3 \%)$ & $2.21 \mathrm{~d}$ & ${ }^{149} \mathrm{Sm}$ \\
${ }^{161} \mathrm{~Tb}$ & 0.593 & $74.60(5.8 \%)$ & $6.88 \mathrm{~d}$ & ${ }^{161} \mathrm{Dy}$ \\
${ }^{166} \mathrm{Ho}$ & 1.855 & $80.57(6.2 \%)$ & $1.11 \mathrm{~d}$ & ${ }^{166} \mathrm{Er}$ \\
${ }^{177} \mathrm{Lu}$ & 0.492 & $208.36(11 \%)$ & $6.73 \mathrm{~d}$ & ${ }^{177} \mathrm{Hf}$ \\
\hline
\end{tabular}

bilization of collagen fibrils, the stimulus-mediated cell secretion, neutrophil chemotaxis and aggregation, etc. [1]-[5] [7]. Lanthanides display strong oxyphilicity and form high thermodynamic stability complexes, especially those derived from poly (aminocarboxilic) acids, which enables them to remain intact while diffusing into extracellular spaces with rapid clearance through kidneys [8]. On the other hand, all lanthanides have similar chemical properties regarding labeling, therefore, radiolanthanides that have been used for therapy, such as ${ }^{153} \mathrm{Sm}$ and ${ }^{177} \mathrm{Lu}$, might easily be replaced with other radiolanthanides in accordance with their application. For example, high energy beta emitters such as ${ }^{149} \mathrm{Pm}$ or ${ }^{166} \mathrm{Ho}$ are efficient for metastases while the low-energy electron emitters as ${ }^{161} \mathrm{~Tb}$ and ${ }^{177} \mathrm{Lu}$ might be suitable for micrometastases therapy [4] [9].

A large number of clinical studies focused on the use of ${ }^{177} \mathrm{Lu}$ for therapeutic treatment have been reported [5] [10]-[13]: ${ }^{177}$ Lu-DOTATOC, ${ }^{177}$ Lu-DOTATATE,${ }^{177}$ Lu-DOTA-HSAM and ${ }^{177}$ Lu-DOTA-Octreotate have been used as receptor-positive tumors [10] [11] [14] [15], ${ }^{177} \mathrm{Lu}$-octreotate in advanced low-grade neuroendocrine tumors [15] [16], ${ }^{177} \mathrm{Lu}-\mathrm{RM} 2$ for prostate cancer [17], ${ }^{177}$ Lu-antitenascin monoclonal antibody (mAb) 81C6 as a targeted radiotherapeutic in patients with brain tumors [18], $\left[{ }^{177} \mathrm{Lu}\right] \mathrm{Lu}-\mathrm{AMBA}$ and ${ }^{177} \mathrm{Lu}$ DOTA-chelated bombesin (BN) as targeted radiotherapy of tumors expressing gastrin releasing peptide receptors [19] [20] or ${ }^{177} \mathrm{Lu}-$ monoclonal antibody (mAb) L8A4 for the treatment of residual tumor margins remaining after surgical debulking of brain tumors [21] [22].

${ }^{161} \mathrm{~Tb}$ is a low-energy $\beta^{-}$emitter similar to ${ }^{177} \mathrm{Lu}$ that has been less used and studied than ${ }^{177} \mathrm{Lu}$. However possesses a high potential for treating small tumor cell clusters or even targeting single cells, due to its ability to emit a significant amount of conversion and Auger electrons, which provides much higher local dose density due to their shorter range in tissue $(0.5-30 \mu \mathrm{m})$. For example, ${ }^{161} \mathrm{~Tb}$-DTPA-octreotide has been reported as a somatostatin analogue for intraoperative scanning [2] [11].

The high beta energy emitter ${ }^{166} \mathrm{Ho}$ has being used with: ${ }^{166} \mathrm{Ho}$-DOTMP, ${ }^{166} \mathrm{Ho}$-EDTMP as bone agent in the treatment of multiple myeloma (for bone marrow ablation) [5] [12] [13], ${ }^{166} \mathrm{Ho}$ macroaggregates such as ${ }^{166} \mathrm{Ho}-$ FHMA or ${ }^{166} \mathrm{Ho}$-poly(L-lactic acid) in radiation synovectomy or hepatic tumors [2] [23] [24], ${ }^{166} \mathrm{Ho}$ and immature DCs to treat irreversible melanoma or as an adjuvant therapy after surgery [25], $\left[{ }^{166} \mathrm{Dy}\right] \mathrm{Dy} /{ }^{166} \mathrm{Ho}$-(EDTMP), from in vivo ${ }^{166} \mathrm{Dy} /{ }^{166} \mathrm{Ho}$ generator system, for myeloablative radiotherapy and subsequent stem cell transplantation [26] or self-expandable covered metallic stent incorporated with ${ }^{166}$ Ho for delivering intraluminal brachytherapy as well as for internal bile drainage in malignant biliary stricture [27].

${ }^{149} \mathrm{Pm}$, a moderate beta energy emitter, has been the least exploited of these radiolanthanides. Just two studies have been reported: ${ }^{149} \mathrm{Pm}$-DO3A-amide- $\beta$ Ala-BBN concerning in vivo tracking of the therapeutic dose [28] and biodistribution studies conducted with ${ }^{149} \mathrm{Pm}$ and ${ }^{177} \mathrm{Lu}$-DOTA-conjugated vitronectin receptor $\left(\alpha_{\mathrm{v}} \beta_{3}\right)$ antagonist-RGD [29].

Carrier-free radiolanthanides of high specific activity can be produced in nuclear reactors via neutron irradiation of massive lanthanide targets ( $>1 \mathrm{mg}$ ), as described in the reaction 1 , followed by a radiochemical separation of the daughter radionuclide $\left({ }_{Z+1}^{A+1} \mathrm{Ln},<1 \mu \mathrm{g}\right)$ from the macro-amounts of the parent target $\left({ }_{Z}^{A} \mathrm{Ln}\right)$ [11] [30]-[37].

$$
{ }_{Z}^{A} \mathrm{Ln}+{ }_{0} n^{1} \rightarrow{ }_{Z}^{A+1} \mathrm{Ln} \stackrel{\beta^{-}}{\longrightarrow}{ }_{Z+1}^{A+1} \mathrm{Ln} \stackrel{\beta^{-}}{\longrightarrow}{ }_{Z+2}^{A+1} \mathrm{Ln}
$$

Considering that the development of potential radiotherapy agents greatly depends on a consistent and reasonably priced supply of high specific activity radiolanthanides (carrier-free), the objective of this work was to develop a device production in order to obtain the carrier free radiolanthanides: ${ }^{149} \mathrm{Pm},{ }^{161} \mathrm{~Tb},{ }^{166} \mathrm{Ho}$ and ${ }^{177} \mathrm{Lu}$. The process, previously developed by our group, is based on radiochemical separation of these radiolanthanides from irradiated natural targets, using an extraction chromatographic resin and for this specific purpose a device was designed and built. 


\section{Separation Process of Radiolanthanides}

The separation conditions of the Nd/Pm, Gd/Tb, Dy/Ho and $\mathrm{Yb} / \mathrm{Lu}$ pairs, shown in Table 2, were selected from the $\mathrm{K}_{\mathrm{d}}$ values of $\mathrm{Nd}, \mathrm{Pm}, \mathrm{Gd}, \mathrm{Tb}, \mathrm{Dy}, \mathrm{Ho}, \mathrm{Yb}$ and $\mathrm{Lu}$ as a function of $\mathrm{HNO}_{3}$ concentration in Ln SPS Eichrom resin (See Figure 1(a)) [38] [39] and the separation factors ( $\alpha$ ) of the Nd/Pm, Gd/Tb, Dy/Ho and Yb/Lu (see Figure 1(b)) pairs calculated from their $K_{d}$ values.

The methodology of radiolanthanide separation is divided into six stages, as outlined in Figure 2: 1) Irradiation of lanthanide nitrates in the nuclear reactor to form the parent/daughter pairs $\left({ }^{149} \mathrm{Nd} /{ }^{149} \mathrm{Pm},{ }^{161} \mathrm{Gd} /{ }^{161} \mathrm{~Tb}\right.$, ${ }^{166} \mathrm{Dy} /{ }^{166} \mathrm{Ho}$ and ${ }^{177} \mathrm{Yb} /{ }^{177} \mathrm{Lu}$ ) (See Table 3), 2) Dissolution of the radioactive salts containing the parent/ daughter pair in $0.15 \mathrm{~mol} / \mathrm{L} \mathrm{HNO}_{3}$ and adsorption into the chromatographic column loaded with Ln SPS Eichrom resin, 3) Desorption of parent by elution with $\mathrm{HNO}_{3}$, 4) Desorption of daughter by elution with $\mathrm{HNO}_{3}$, 5) Precipitation of lanthanide hydroxides $\mathrm{Ln}(\mathrm{OH})_{3}$ by addition of $\mathrm{NaOH}$ to daughter's eluate, and 6) Re-dissolution of lanthanide hydroxides $\mathrm{Ln}(\mathrm{OH})_{3}$ with $0.1 \mathrm{~mol} / \mathrm{L} \mathrm{HCl}$.

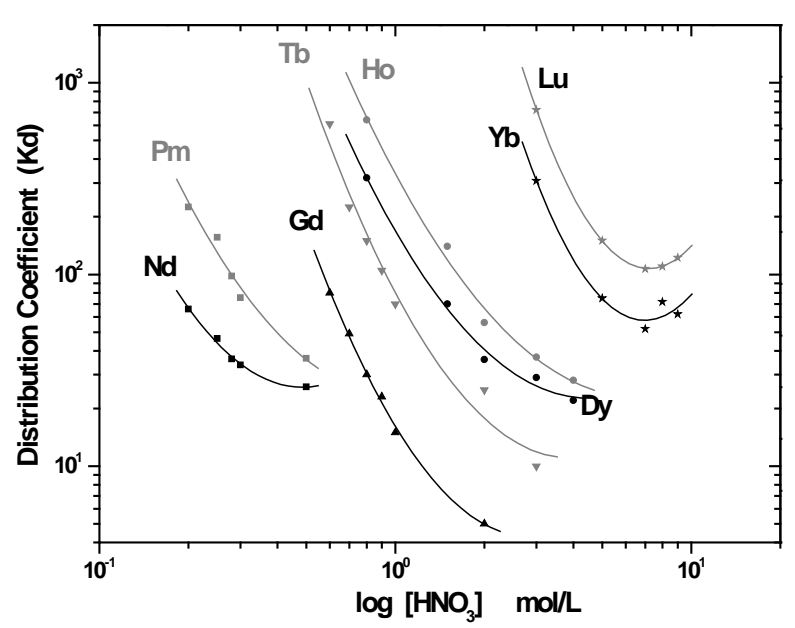

(a)

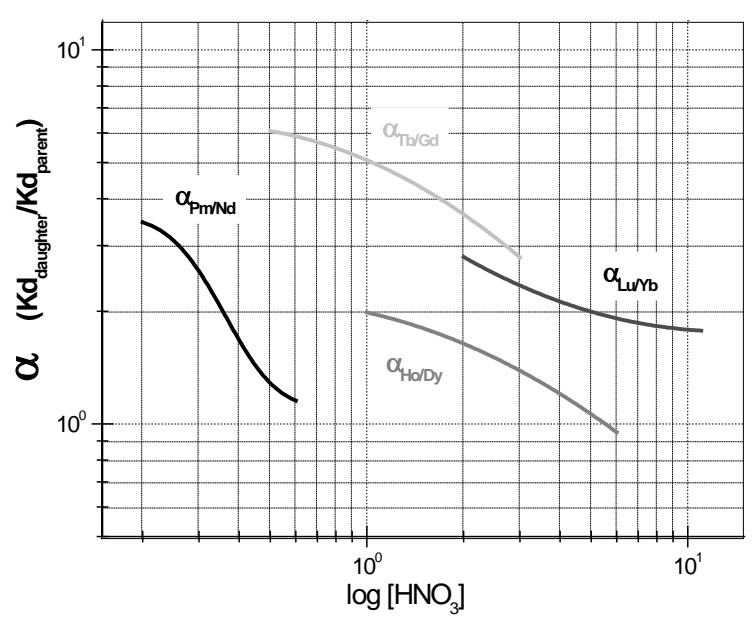

(b)

Figure 1. (a) Effect of $\mathrm{HNO}_{3}$ concentration on the distribution coefficients of Nd, Pm, Gd, Tb, Gd, Ho, Yb and Lu in Ln SPS Eichrom resin; (b) Separation factors $(\alpha)$ of the Nd/Pm, Gd/Tb, Dy/Ho and Yb/Lu pairs in Ln SPS Eichrom resin as a function of $\left[\mathrm{HNO}_{3}\right][37][38]$.

Table 2. Separation conditions of the Nd/Pm, Gd/Tb, Dy/Ho and $\mathrm{Yb} / \mathrm{Lu}$ pairs.

\begin{tabular}{ccccc}
\hline Pair & $\begin{array}{c}{\left[\mathrm{HNO}_{3}\right] \mathrm{mol} / \mathrm{L}} \\
\text { recovery parent }\end{array}$ & $\begin{array}{c}{\left[\mathrm{HNO}_{3}\right] \text { mol/L }} \\
\text { recovery daughter }\end{array}$ & $\begin{array}{c}\text { Separation } \\
\text { efficiency }(\%)\end{array}$ & $\begin{array}{c}\text { Radionuclide purity } \\
\text { of daughter }(\%)\end{array}$ \\
\hline $\mathrm{Gd} / \mathrm{Tb}$ & 0.80 & 3.0 & 100 & 100 \\
$\mathrm{Nd} / \mathrm{Pm}$ & 0.18 & 1.5 & 98.4 & 99.9 \\
$\mathrm{Dy} / \mathrm{Ho}$ & 1.40 & 1.4 & 100 & 100 \\
$\mathrm{Yb} / \mathrm{Lu}$ & 3.40 & 8.0 & 89.72 & 99.9 \\
\hline
\end{tabular}

Table 3. Irradiation conditions of Nd, Gd, Dy and Yb targets to produce ${ }^{149} \mathrm{Pm},{ }^{161} \mathrm{~Tb},{ }^{166} \mathrm{Ho}$ and ${ }^{177} \mathrm{Lu}$.

\begin{tabular}{|c|c|c|c|c|}
\hline $\begin{array}{l}\text { Enriched } \\
\text { isotope }\end{array}$ & Nuclear reaction & $\begin{array}{l}\text { Irradiation } \\
\text { time }\end{array}$ & $\begin{array}{l}\text { Decay } \\
\text { time }\end{array}$ & $\begin{array}{c}\text { Activity } \\
\text { specific } \mathrm{MBq} / \mathrm{mg}\end{array}$ \\
\hline $\begin{array}{l}{ }^{148} \mathrm{Nd} \\
90.1 \%\end{array}$ & ${ }^{148} \mathrm{Nd}(n, \gamma){ }^{149} \mathrm{Nd} \underset{1.73 \mathrm{~h}}{\stackrel{\beta^{-}}{\longrightarrow}}{ }^{149} \mathrm{Pm} \underset{2.2 \mathrm{~d}}{\stackrel{\beta^{-}}{\longrightarrow}}{ }_{\text {stable }}^{149} \mathrm{Sm}$ & $18 \mathrm{~h}$ & $8 \mathrm{~h}$ & 7.5 \\
\hline $\begin{array}{l}{ }^{160} \mathrm{Gd} \\
97.2 \%\end{array}$ & ${ }^{160} \mathrm{Gd}(n, \gamma){ }^{161} \mathrm{Gd} \underset{3.7 \min }{\stackrel{\beta^{-}}{\longrightarrow}}{ }^{161} \mathrm{~Tb} \underset{17.6 \mathrm{~h}}{\stackrel{\beta^{-}}{\longrightarrow}}{ }_{\text {stable }}^{161} \mathrm{Dy}$ & $24 \mathrm{~h}$ & $1 \mathrm{~h}$ & 4.5 \\
\hline $\begin{array}{l}{ }^{164} \mathrm{Dy} \\
99 \%\end{array}$ & ${ }^{164} \operatorname{Dy}(n, \gamma){ }_{1.25 \min }^{165} \operatorname{Dy}(n, \gamma){ }^{166} \mathrm{Dy} \underset{81.6 \mathrm{~h}}{\stackrel{\beta^{-}}{\longrightarrow}}{ }^{166} \mathrm{Ho} \underset{26.76 \mathrm{~h}}{\stackrel{\beta^{-}}{\longrightarrow}}{ }_{\text {stable }}^{166} \mathrm{Er}$ & $20 \mathrm{~h}$ & $2 \mathrm{~d}$ & 5 \\
\hline $\begin{array}{l}{ }^{176} \mathrm{Yb} \\
95.3 \%\end{array}$ & ${ }^{176} \mathrm{Yb}(n, \gamma){ }^{177} \mathrm{Yb} \underset{{ }_{1.9 \mathrm{~h}}}{\stackrel{\beta^{-}}{\longrightarrow}}{ }^{177} \mathrm{Lu} \underset{{ }_{6.734 \mathrm{~d}}}{\stackrel{\beta^{-}}{\longrightarrow}}{ }_{\text {stable }}^{177} \mathrm{Hf}$ & $4 \mathrm{~h}$ & $20 \mathrm{~h}$ & 9 \\
\hline
\end{tabular}




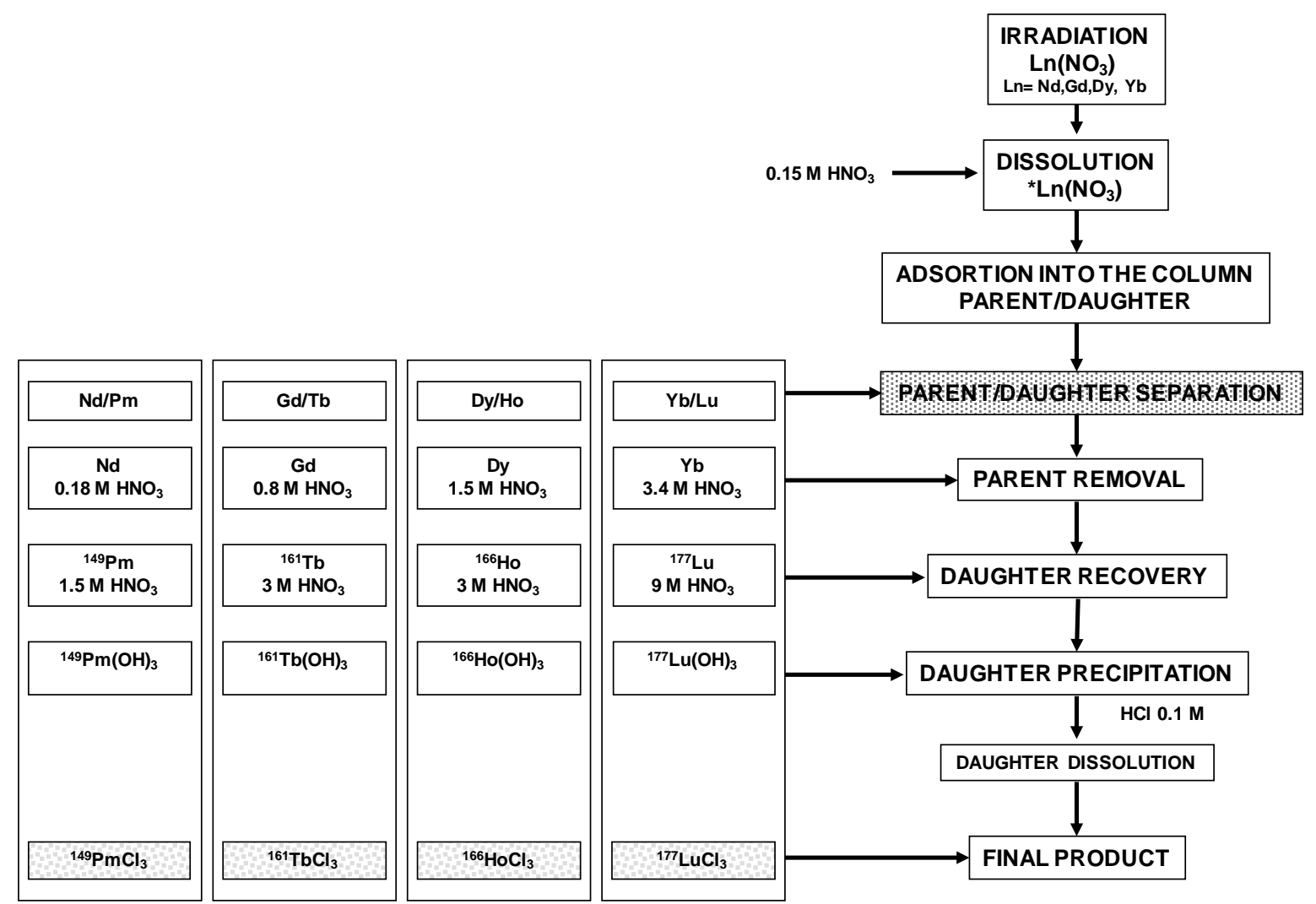

Figure 2. Separation protocol by produce ${ }^{149} \mathrm{Pm},{ }^{161} \mathrm{~Tb},{ }^{166} \mathrm{Ho}$ and ${ }^{177} \mathrm{Lu}$.

Radiolanthanides are produced by irradiation of $50 \mathrm{mg}{ }^{148} \mathrm{Nd}\left(\mathrm{NO}_{3}\right)_{3},{ }^{160} \mathrm{Gd}\left(\mathrm{NO}_{3}\right)_{3},{ }^{164} \mathrm{Dy}\left(\mathrm{NO}_{3}\right)_{3}$ and ${ }^{176} \mathrm{Yb}\left(\mathrm{NO}_{3}\right)_{3}$ in the TRIGA MARK III Reactor of the National Institute of the Nuclear Research (ININ) in Mexico, to a neutron fluence rate of $1 \times 10^{13} \mathrm{n} \mathrm{cm}^{-2} \cdot \mathrm{s}^{-1}$, under the conditions marked in Table 3 .

The parent lanthanide of the parent/daughter pairs: Nd/Pm, Gd/Tb, Dy/Ho and $\mathrm{Yb} / \mathrm{Lu}$ is eluted at first during the chromatographic separation process. This solution can be re-crystallized as nitrate and the enriched target recover for a new irradiation. The ${ }^{149} \mathrm{Pm},{ }^{161} \mathrm{~Tb},{ }^{166} \mathrm{Ho}$ and ${ }^{177} \mathrm{Lu}$ solutions obtained at high concentrations of nitric acid (3 to $8 \mathrm{M}$ ) are transformed to lanthanide chloride salts by adding $\mathrm{NaOH}$, until reaching a pH value of 7 to form lanthanide hydroxides $\mathrm{Ln}(\mathrm{OH})_{3}$, which were re-dissolved in $4 \mathrm{~mL}$ of $0.1 \mathrm{~N} \mathrm{HCl}$ to get lanthanide chlorides solutions $\left({ }^{149} \mathrm{PmCl}_{3},{ }^{161} \mathrm{TbCl}_{3},{ }^{166} \mathrm{HoCl}_{3}\right.$ and $\left.{ }^{177} \mathrm{LuCl}_{3}\right)$ carrier-free with a radionuclide purity higher than 99.9\%.

\section{Radiolanthanide Separation Device}

The radiolanthanide separation device, called DISER, was designed and built from separation methodology described previously, for routinely production of carrier-free ${ }^{149} \mathrm{Pm},{ }^{161} \mathrm{~Tb}$, ${ }^{166} \mathrm{Ho}$ and ${ }^{177} \mathrm{Lu}$ with a radionuclide purity of more than 99.9\%. The DISER was built at the National Institute of Nuclear Research (ININ) in Mexico by groups from the Radioactive Materials Research Laboratory (LIMR) and the Prototype Fabrication Department. The device subsequently described is the result of several arrangements and modifications.

The DISER was placed in a hot cell consisted of 1) Labware support stands, 2) Chromatographic columns support stand, 3) Reagent Access System and 4) Opening system of the irradiation container (see Figure 3). A description of each component and system is presented below.

Labware support stand. The DISER has three acrylic support stands, two are held at the top of the cell to place beakers used in the separation process (A1). Both support stands are rotatory in order to facilitate the handling and arrangement of labware during the process. The third is placed on the left wall of the cell and is constituted by eight semi-hollow cylindrical bases where the chromatographic columns are stocked (A2) (see Figure 3$)$. 


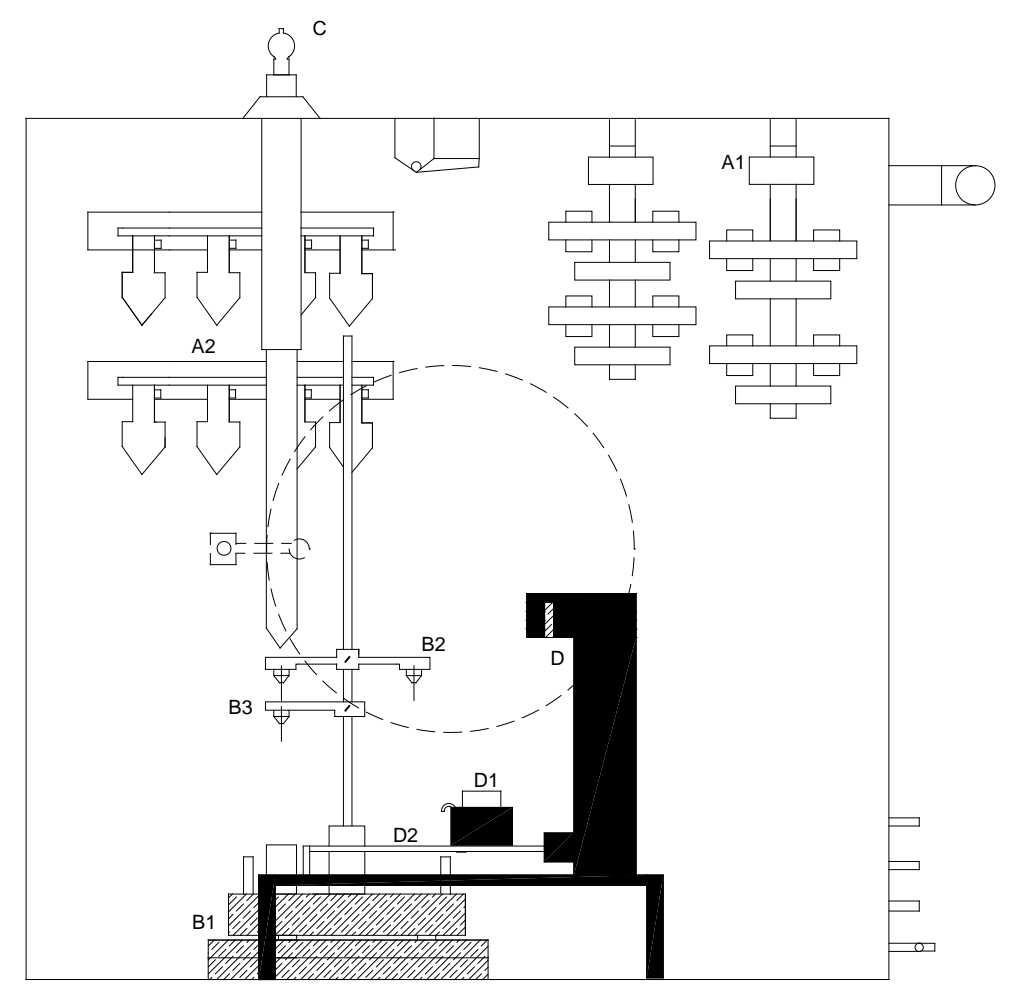

Figure 3. DISER: Radiolanthanide separation device.

Chromatographic columns support carousel. The support carousel is the DISER's core and is there where the separation processes of the parent/daughter pairs $\left({ }^{149} \mathrm{Nd} /{ }^{149} \mathrm{Pm},{ }^{161} \mathrm{Gd} /{ }^{161} \mathrm{~Tb},{ }^{166} \mathrm{Dy} /{ }^{166} \mathrm{Ho}\right.$ and $\left.{ }^{177} \mathrm{Yb} /{ }^{177} \mathrm{Lu}\right)$ is performed. The carousel is constructed all in acrylic and its stainless steel shaft is screwed onto the cell (see Figure 3). The support carousel consists of: 1) a rotating disk which can hold beakers to receive the eluates from the separation process (B1) and 2) two supports fixed on the carousel's shaft, one holds 2 chromatographic columns for the separation process and dissolution of lanthanide hydroxides (B2), and the other one in shape of funnel to add the $\mathrm{NaOH}$ to the daughter's eluates (B3). This neutralization reaction is air-cooled. The columns base is also gyratory and can be fitted to varing heights.

The glass chromatographic columns $(80 \times 12 \mathrm{~mm})$ with a coarse fritted disc are used in the separation process - packaged with $2 \mathrm{~g}$ of Eichrom's Ln SPS resin $(50-100 \mu \mathrm{m})$-and the dissolution of lanthanide hydroxides, filled with glass wool and Whatman No.1 filter paper.

Reagent Access System is located outside the hot cell, at the top and consists of a glass separatory funnel with cap and stopcork holded to an acrilic support (C). The funnel tip is connected to a glass pipette located directly on the chromatographic column. This system allows to introduce to the cell the $\mathrm{HNO}_{3}$ solutions requiered for the separation and dissolution process, easily and safely without openning the hot cell.

Opening system of the irradiation container. The radioactive lanthanide nitrate salts contained in quartz ampoules are uncapped in the opening system. The latter is constituted by an acrylic support in the form of inverted "L" (D); the ampoule is held into the large base (D1) which can slide and in the cutter ampoule base (D2) the tip of the quartz ampoule is inserted into the hole opener and by applying a torque, the top is cracked.

\section{Production of Radiolanthanides in the DISER}

\section{Before separation process}

The DISER is perfectly cleaned; the chromatographic columns (Wheaton $80 \times 12 \mathrm{~mm}$ ) are packed with with Ln SPS Eichrom resin (B2) and with glass wool and Whatman No. 1 filter paper (B3). All solutions are prepared: $\mathrm{HNO}_{3}$ solutions and $4 \mathrm{~mol} / \mathrm{L} \mathrm{HCl}$. The chromatographic columns are placed into the Labware support stand (A2), the beakers properly numbered and the final product vial into the carousel (B1) and the $\mathrm{NaOH}$ pearls and the $0.15 \mathrm{~mol} / \mathrm{L} \mathrm{HNO}_{3}$ solution into support stands (A1). 


\section{Separation Process}

a) The ampoule containing the radioactive nitrate salt is introduced into the DISER and placed in the support (D2) of the opening system (D). The ampoule is then opened, as shown in Figure 4.

b) Radioactive nitrate salt $\left[{ }^{\mathrm{n}} \mathrm{Ln}\left(\mathrm{NO}_{3}\right)_{3} /{ }^{*(\mathrm{n}+1)} \mathrm{Ln}\left(\mathrm{NO}_{3}\right)_{3}\right]$ is then dissolved by $0.15 \mathrm{~mol} / \mathrm{L} \mathrm{HNO}_{3}$ and this solution is added to the separation column (B2) using a Pasteur pipette.

c) $0.15 \mathrm{~mol} / \mathrm{L} \mathrm{HNO}_{3}$ is added to the reservoir of the Reagent Access System (C), which is then opened to introduce this solution to the separation column (B2). Eluates are recovered in the beaker No. 1.

d) The separation column (B2) is aligned to the position of the beaker No. 2 and the corresponding solution of $\mathrm{HNO}_{3}$ used to desorb the parent radiolanthanide (see Figure 2) is loaded to the Reagent Access System (C). This solution is added to the chromatographic separation column (B2) and the eluate, contained the parent radiolanthanide, is recovered in the beaker No. 2 .

e) Separation column (B2) is rotated to the position of the beaker No. 3, the Reagent Access System (C) is loaded with the nitric acid solution to desorb the daughter radiolanthanide (Figure 2) and the eluate contained the daughter radiolanthanide, is recovered in the beaker No. 3.

f) Sodium hydroxide pearls are added slowly to the beaker No. 3 to until complete dissolution of $\mathrm{NaOH}$.

g) The recovery column (B3) is turned to the position of the beaker No. 4, and the content of the beaker No. 3 is added to the column. Liquid phase is recovered in the beaker No. 4 and the solid phase constituted by the daughter radiolanthanide hydroxide remains into the column.

h) The recovery column (B3) is rotated to align to the final product vial and the Reagent Access System (C) is loaded with $0.1 \mathrm{M} \mathrm{HCl}$. This solution is then added to the recovery column (B3) and after 10 minutes of contact, in order to completely dissolve the lanthanide hydroxides, the column is open and the liquid phase, contained the lanthanides chlorides is finally recovered in the final product vial.

The separation efficiency and the radionuclide purities are then determined to the final product with a coaxial gamma detector HPGe (Canberra 7229P) connected to a PC-multichannel analyzer (ACCUSSPECT-A, Canberra). Chemical purity should be determined by ICP.

\section{Discussion}

Radiochemical separations of the ${ }^{149} \mathrm{Pm},{ }^{161} \mathrm{~Tb},{ }^{166} \mathrm{Ho}$ and ${ }^{177} \mathrm{Lu}$ from the macro-amounts of the neodinium, gadolinium, dysprosium and ytterbium targets, performed in the DISER by the methodology proposed, allow to separate: 1) Gadolinium and Terbium with an efficiency of $100 \%$, recovering the ${ }^{161} \mathrm{~Tb}$ with a radionuclide purity of $100 \%$; 2) Neodymium and Promethium with an efficiency of $98.4 \%$ and a ${ }^{149} \mathrm{Pm}$ radionuclide purity of 99.9\%; 3) Dysprosium and Holmium with an efficiency of $100 \%$, obtaining $100 \%$ pure ${ }^{166}$ Ho; and 4) Ytterbium and Lutetium with an efficiency of $89.7 \%$, recovering the ${ }^{177} \mathrm{Lu}$ at a $99.9 \%$ radionuclide purity if the first $6 \mathrm{~mL}$ of the ${ }^{177}$ Lu eluate are removed.

The recovery efficiencies of the lanthanides chlorides after precipitation of the hydroxides and the dissolution with $0.1 \mathrm{~mol} / \mathrm{L} \mathrm{HCl}$ are: $98.5 \%, 96.5 \%, 96.9 \%$ and $99.6 \%$ for ${ }^{149} \mathrm{Pm},{ }^{161} \mathrm{~Tb},{ }^{166} \mathrm{Ho}$ and ${ }^{177} \mathrm{Lu}$ respectively. The remotion of
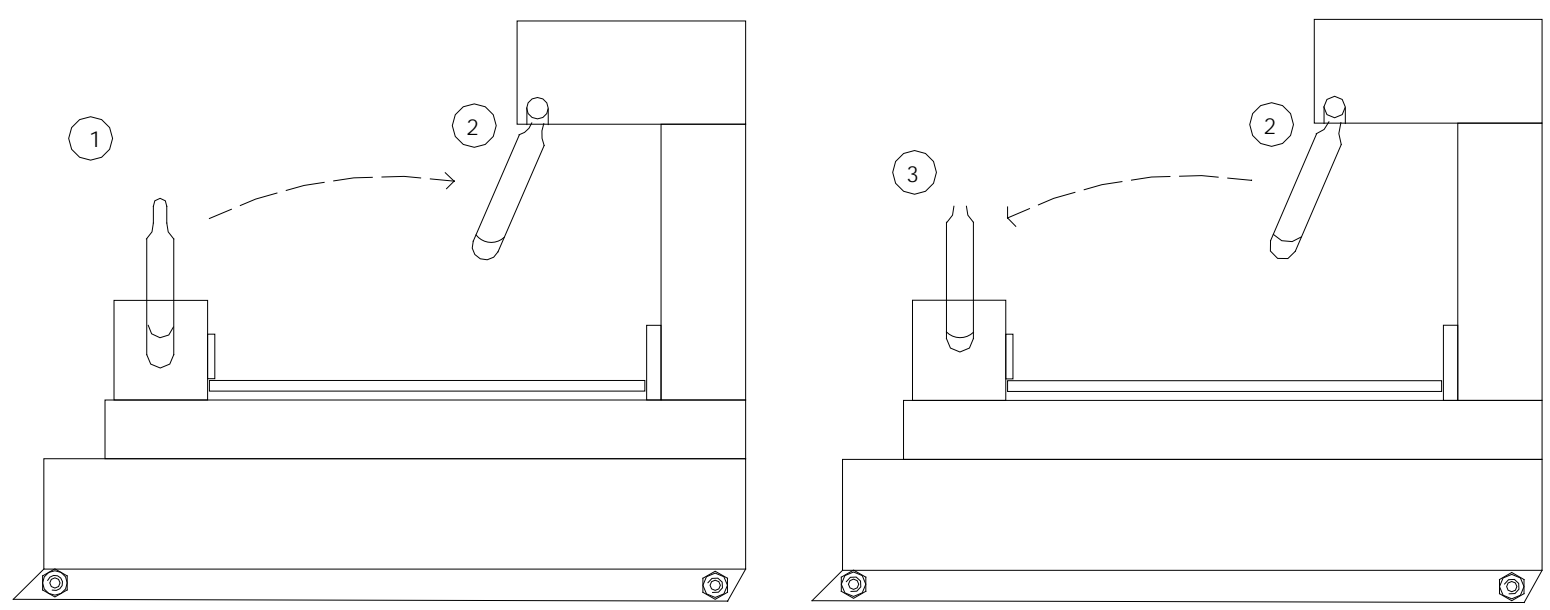

Figure 4. Opening system of the irradiation container. 
$\mathrm{HNO}_{3}$ is commonly performed by evaporation to dryness; however, this process consumes time, requires the installation of a heating equipment inside the hot cell and produces highly corrosive vapors $\left(\mathrm{NO}_{\mathrm{x}}\right)$ by the decomposition of nitric acid. To avoid these drawbacks, the eluates of $\mathrm{Ln}\left(\mathrm{NO}_{3}\right)_{3}\left(\mathrm{Ln}={ }^{149} \mathrm{Pm},{ }^{161} \mathrm{~Tb},{ }^{166} \mathrm{Ho}\right.$ and $\left.{ }^{177} \mathrm{Lu}\right)$ were transformed to lanthanides hydroxides $\left[\mathrm{Ln}(\mathrm{OH})_{3}\right]$, and dissolved in $0.1 \mathrm{M} \mathrm{HCl}$ [40]:

$$
\begin{gathered}
\mathrm{Ln}\left(\mathrm{NO}_{3}\right)_{3}+3 \mathrm{NaOH} \Leftrightarrow \mathrm{Ln}(\mathrm{OH})_{3} \downarrow+3 \mathrm{NaNO}_{3} \\
\mathrm{Ln}(\mathrm{OH})_{3} \downarrow+3 \mathrm{HCl} \Leftrightarrow \mathrm{LnCl}_{3}+3 \mathrm{H}_{2} \mathrm{O}
\end{gathered}
$$

The sodium nitrate salts are removed in the aqueous phase and only the hydroxide precipitates are redissolved. In the separation protocol proposed, the $\mathrm{pH}$ values to precipitate the lanthanide nitrate solutions was fixed at 7 , considering that the $\mathrm{pH}$ values reported by the literature, at which lanthanides precipitate are: $\mathrm{Nd}$ (6.7), $\mathrm{Pm}(6.6)$, Gd(6.4), Tb (6.3), Dy (6.1), Ho (6.1), Yb (5.6) and Lu (5.5), values lower than 7 [40].

\section{Conclusion}

A radiolanthanide separation device (DISER) was designed and built to standardize the separation process of the four pairs: ${ }^{149} \mathrm{Nd} /{ }^{149} \mathrm{Pm},{ }^{161} \mathrm{Gd} /{ }^{161} \mathrm{~Tb},{ }^{166} \mathrm{Dy} /{ }^{166} \mathrm{Ho},{ }^{177} \mathrm{Yb} /{ }^{177} \mathrm{Lu}$ in order to obtain carrier-free ${ }^{149} \mathrm{Pm},{ }^{161} \mathrm{~Tb},{ }^{166} \mathrm{Ho}$ or ${ }^{177} \mathrm{Lu}$. The separation process of pairs reported here consists to six stages: 1) Target Irradiation; 2) Dissolution of the irradiated target to be loaded into the chromatographic column; 3) Desorption of parent; 4) Desorption of daughter; 5) Formation of lanthanide hydroxides; and 6) Re-dissolution of lanthanide hydroxides with HCl. The adequate execution of this process, for a period of 20 - $25 \mathrm{~min}$, is able to produce carrier-free ${ }^{149} \mathrm{Pm},{ }^{161} \mathrm{~Tb},{ }^{166} \mathrm{Ho}$ or ${ }^{177} \mathrm{Lu}$ and with a radionuclide purity of more than $99.9 \%$. It is important to remark that for an optimal performance is important to use the following separation conditions: for Neodymium and Promethium use 0.18 and $1.5 \mathrm{M} \mathrm{HNO}_{3}$, for Gadolinium and Terbium use 0.8 and $3 \mathrm{M} \mathrm{HNO}_{3}$, for Dysprosium and Holmium use $1.5 \mathrm{M}$ $\mathrm{HNO}_{3}$ and for Ytterbium and Lutetium use 3.4 and $8 \mathrm{M} \mathrm{HNO}_{3}$ respectively.

\section{Acknowledgements}

The authors indebted to the technical staff of reactor Triga Mark III (Mexico): Maximiano Hernández, Wenceslao Nava, Margarito Alva, Braulio Ortega, Edgar Herrera and Roberto Raya; and Angel Jesus Juárez Neri by drawing DISER.

\section{Funding}

This work was supported by the "Consejo Nacional de Ciencia y Tecnología” grant number: CONACYTSALUD-2004-C01-001.

\section{References}

[1] Anderson, C.J. and Welch, M.J. (1999) Radiometal-Labeled Agents (Non-Technetium) for Diagnostic Imaging. Chemical Reviews, 99, 2219-2234. http://dx.doi.org/10.1021/cr980451q

[2] Nayak, D. and Lahiri, S. (1999) Application of Radioisotopes in the Field of Nuclear Medicine: I. Lanthanide Series Elements. Journal of Radioanalytical and Nuclear Chemistry, 242, 423-432. http://dx.doi.org/10.1007/BF02345573

[3] Volkert, W.A. and Hoffman, T.J. (1999) Therapeutic Radiopharmaceuticals. Chemical Reviews, 99, 2269-2292. http://dx.doi.org/10.1021/cr9804386

[4] Unak, P. (2002) Targeted Tumor Radiotherapy. Brazilian Archives of Biology and Technology, 45, 97-110. http://dx.doi.org/10.1590/S1516-89132002000500014

[5] Ehrhardt, G.J., Ketring, A.R. and Ayers, L.M. (1998) Reactor-Produced Radionuclides at the University of Missouri Research Reactor. Applied Radiation and Isotopes, 49, 295-297. http://dx.doi.org/10.1016/S0969-8043(97)00038-9

[6] Smith, C.J., Volkert, W.A. and Hoffman, T.J. (2005) Radiolabeled Peptide Conjugates for Targeting of the Bombesin Receptor Superfamily Subtypes. Nuclear Medicine and Biology, 32, 733-740. http://dx.doi.org/10.1016/j.nucmedbio.2005.05.005

[7] Evans, C.H. (1983) Interesting and Useful Biochemical Properties of Lanthanides. TIBS, 445-449. http://dx.doi.org/10.1016/0968-0004(83)90032-4

[8] Sturza, C.M., Boscencu, R. and Nacea, V. (2010) The Lanthanides: Physicochemical Properties Relevant for Their 
Biomedical Applications. ChemInform, 41, 26. http://dx.doi.org/10.1002/chin.201026245

[9] Uusijarvi, H., Bernhardt, P., Rosch, F., Maecke, H.R. and Forssell-Aronsson, E. (2006) Electron- and Positron-Emitting Radiolanthanides for Therapy: Aspects of Dosimetry and Production. Journal of Nuclear Medicine, 47, 807-814.

[10] Milenic, D.E., Garmestani, K., Chappell Lara, L., Dadachova, E., Yordanov, A., Ma, D.S., Schlom, J. and Brechbiel, M.W. (2002) In Vivo Comparison of Macrocyclic and Acyclic Ligands for Radiolabeling of Monoclonal Antibodies with ${ }^{177} \mathrm{Lu}$ for Radioimmunotherapeutic Applications. Nuclear Medicine and Biology, 29, 431-442. http://dx.doi.org/10.1016/S0969-8051(02)00294-9

[11] Lehenberger, S., Barkhausen, C., Cohrs, S., Fischer, E., Grunberg, J., Hohn, A., Koster, U., Schibli, R., Turler, A. and Zhernosekov, K. (2011) The Low-Energy $\beta^{-}$and Electron Emitter ${ }^{161} \mathrm{~Tb}$ as an Alternative to ${ }^{177} \mathrm{Lu}$ for Targeted Radionuclide Therapy. Nuclear Medicine and Biology, 38, 917-924.

http://dx.doi.org/10.1016/j.nucmedbio.2011.02.007

[12] Louw, W.K.A., Dormehl, I.C., van Rensburg, A.J., Hugo, N., Alberts, A.S., Forsyth, O.E., Beverley, G., Sweetlove, M.A., Marais, J., Lötter, M.G. and Van Aswegen, A. (1996) Evaluation of Samarium-153 and Holmium-166-EDTMP in the Normal Baboon Model. Nuclear Medicine and Biology, 23, 935-940. http://dx.doi.org/10.1016/S0969-8051(96)00117-5

[13] Abbasi, I.A. (2011) Studies on ${ }^{177}$ Lu-Labeled Methylene Diphosphonate as Potential Bone-Seeking Radiopharmaceutical for Bone Pain Palliation. Nuclear Medicine and Biology, 38, 417-425. http://dx.doi.org/10.1016/j.nucmedbio.2010.09.013

[14] Wunderlich, G., Schiller, E., Bergmann, R. and Pietzsch, H.J. (2010) Comparison of the Stability of Y-90-, Lu-177and Ga-68-Labeled Human Serum Albumin Microspheres (DOTA-HSAM). Nuclear Medicine and Biology, 37, 861867. http://dx.doi.org/10.1016/j.nucmedbio.2010.05.004

[15] Borson-Chazot, F. (2006) Radiothérapie métabolique des tumeurs endocrines gastro-entéro-pancréatiques par les analogues radio-marqués de la somatostatine. Annales d'Endocrinologie, 67, 198-204. http://dx.doi.org/10.1016/S0003-4266(06)72587-2

[16] Claringbold, P., Brayshaw, P., Price, R. and Turner, J.H. (2011) 6605 POSTER Phase l-ll Study of Radiopeptide ${ }^{177}$ LuOctreotate in Combination with Capecitabine and Temozolomide in Advanced Low-Grade Neuroendocrine Tumours. European Journal of Cancer, 41, S473. http://dx.doi.org/10.1016/S0959-8049(11)71916-5

[17] Mansi, R., Dumont, R.A., Tamma, M.L., Deininger, F., Borkowski, S., Maecke, H.R. and Weber, W.A. (2011) 7037 POSTER Radiopeptide Therapy of Prostate Cancer LU-177-RM2 (BAY 1017858) Monotherapy and in Combination with PKI Inhibitors. European Journal of Cancer, 47, S495.

[18] Yordanov, A.T., Hens, M., Pegram, C., Bigner, D.D. and Zalutsky, M.R. (2007) Antitenascin Antibody 81C6 Armed with ${ }^{177}$ Lu: In Vivo Comparison of Macrocyclic and Acyclic Ligands. Nuclear Medicine and Biology, 34, 173-183. http://dx.doi.org/10.1016/j.nucmedbio.2006.11.003

[19] Chen, J.Q., Linder, K.E., Cagnolini, A., Metcalfe, E., Raju, N., Tweedle, M.F. and Swenson, R.E. (2008) Synthesis, Stabilization and Formulation of $\left[{ }^{177} \mathrm{Lu}\right] \mathrm{Lu}-\mathrm{AMBA}$, a Systemic Radiotherapeutic Agent for Gastrin Releasing Peptide Receptor Positive Tumors. Applied Radiation and Isotopes, 66, 497-505. http://dx.doi.org/10.1016/j.apradiso.2007.11.007

[20] Koumarianou, E., Mikołajczak, R., Pawlak, D., Zikos, X., Bouziotis, P., Garnuszek, P., Karczmarczyk, U., Maurin, M. and Archimandritis, S.C. (2009) Comparative Study on DOTA-Derivatized Bombesin Analog Labeled with ${ }^{90} \mathrm{Y}$ and ${ }^{177} \mathrm{Lu}$ : In Vitro and in Vivo Evaluation. Nuclear Medicine and Biology, 36, 591-603. http://dx.doi.org/10.1016/j.nucmedbio.2009.03.006

[21] Hens, M., Vaidyanathan, G., Zhao, X.-G., Bigner, D.D. and Zalutsky, M.R. (2010) Anti-EGFRvIII Monoclonal Antibody Armed with ${ }^{177} \mathrm{Lu}$ : In Vivo Comparison of Macrocyclic and Acyclic Ligands. Nuclear Medicine and Biology, 37, 741-750. http://dx.doi.org/10.1016/j.nucmedbio.2010.04.020

[22] Hens, M., Vaidyanathan, G., Welsh, P. and Zalutsky, M.R. (2009) Labeling Internalizing Anti-Epidermal Growth Factor Receptor Variant III Monoclonal Antibody with ${ }^{177} \mathrm{Lu}$ : In Vitro Comparison of Acyclic and Macrocyclic Ligands. Nuclear Medicine and Biology, 36, 117-128. http://dx.doi.org/10.1016/j.nucmedbio.2008.11.001

[23] Park, K.B., Kim, J.R. and Lambrecht, R. (1996) Preparation of Dysprosium-165/Holmium-166 Macroaggregate for Radiation Synovectomy. Journal of Radioanalytical and Nuclear Chemistry, 206, 5-16. http://dx.doi.org/10.1007/BF02040036

[24] Mäkelä, O., Penttilä, P., Kolehmainen, E., Sukura, A., Sankari, S. and Tulamo, R.M. (2002) Experimental Radiation Synovectomy in Rabbit Knee with Holmium-166 Ferric Hydroxide Macroaggregate. Nuclear Medicine and Biology, 29, 593-598. http://dx.doi.org/10.1016/S0969-8051(02)00317-7

[25] Lee, T.-H., Cho, Y.-H., Lee, J.D., Yang, W.I., Shin, J.L. and Lee, M.-G. (2006) Enhanced Antitumor Effect of Dendritic Cell Based Immunotherapy after Intratumoral Injection of Radionuclide Ho-166 against B16 Melanoma. Immu- 
nology Letters, 106, 19-26. http://dx.doi.org/10.1016/j.imlet.2006.03.007

[26] Pedraza-López, M., Ferro-Flores, G., de Murphy C.A., Morales-Ramírez, P., Piedras-Rosas, J., Murphy-Stack, E. and Hernández-Oviedo, O. (2004) Cytotoxic and Genotoxic Effect of the $\left[{ }^{166}\right.$ Dy]Dy ${ }^{166}$ Ho-EDTMP in Vivo Generator System in Mice. Nuclear Medicine and Biology, 31, 1079-1085. http://dx.doi.org/10.1016/j.nucmedbio.2004.08.010

[27] Won, J.H., Lee, J.D., Wang, H.J., Han, J.H., Kim, J.H., Kim, K.-H., Itkin, M. and Park, K.B. (2005) Effects of a Holmium-166 Incorporated Covered Stent Placement in Normal Canine Common Bile Ducts. Journal of Vascular and Interventional Radiology, 16, 705-711.

[28] Hu, F., Cutler, C.S., Hoffman, T., Sieckman, G., Volkert, W.A. and Jurisson, S.S. (2002) Pm-149 DOTA Bombesin Analogs for Potential Radiotherapy: In Vivo Comparison with Sm-153 and Lu-177 Labeled DO3A-Amide- $\beta$ AlaBBN(7-14) $\mathrm{NH}_{2}$. Nuclear Medicine and Biology, 29, 423-430. http://dx.doi.org/10.1016/S0969-8051(02)00290-1

[29] Engelbrecht, H., Forbis, L., Liu, S., Lewis, M., Lever, J., Watkinson, L., Carmack, T., Ketring, A. and Cutler, C. (2007) Biodistribution Studies Conducted with Pm-149 and Lu-177-DOTA-Conjugated Vitronectin Receptor $\left(\alpha_{v} \beta_{3}\right)$ AntagonistRGD. Journal of Nuclear Medicine, 48, 296.

[30] Godoy, N.O., Pinto, L.N. and Avila, M.J. (2002) The Ho-166 and Lu-177 Production for Nuclear Medicine Applications at the RECH-1. Alasbimn Journal, 5, 1-2.

[31] Ketring, R., Ehrhardt, G.J., Embree, M.F., Bailey, K.D., Tyler, T.T., Gawenis, J.A., Jurisson, S.S., Engelbrecht, H.P., Smith, C.J. and Cuttler, C.S. (2003) Production and Supply of High Specific Activity Radioisotopes for Radiotherapy Applications. Alasbimn Journal, 5, 1-6.

[32] Ferro-Flores, G., de Murphy C.A., Pedraza-López, M., Monroy-Guzmán, F., Meléndez-Alafort, L., Tendilla, J.I. and Jiménez-Varela, R. (2003) Labeling of Biotin with $\left[{ }^{166} \mathrm{Dy}\right] \mathrm{Dy} /{ }^{166} \mathrm{Ho}$ as a Stable in Vivo Generator System. International Journal of Pharmaceutics, 255, 129-138. http://dx.doi.org/10.1016/S0378-5173(03)00052-8

[33] Lebedev, N.A., Novgorodov, A.F., Misiak, R., Brockmann, J. and Rösch, F. (2000) Radiochemical Separation of No-Carrier-Added ${ }^{177} \mathrm{Lu}$ as Produced via the ${ }^{176} \mathrm{Yb}(n, \gamma){ }^{177} \mathrm{Yb} \rightarrow{ }^{177} \mathrm{Lu}$ Process. Applied Radiation and Isotopes, 53, 421425. http://dx.doi.org/10.1016/S0969-8043(99)00284-5

[34] Roig, O., Bélier, G., Daugas, J.M., Delbourgo, P., Maunoury, L., Méot, V., Morichon, E., Sauvestre, J.E., Aupiais, J., Boulin, Y., Fioni, G., Letourneau, A., Marie, F. and Ridikas, D. (2004) High Spin K Isomeric Target of ${ }^{177 \mathrm{~m}} \mathrm{Lu}$. Nuclear Instruments and Methods in Physics Research Section A, 521, 5-11. http://dx.doi.org/10.1016/j.nima.2003.11.140

[35] Dadachova, E., Mirzadeh, S., Smith, S.V., Knapp, F.F. and Hetherington, E.L. (1997) Radiolabeling Antibodies with Holmium-166. Applied Radiation and Isotopes, 48, 477-481. http://dx.doi.org/10.1016/S0969-8043(96)00269-2

[36] Pillai, M.R.A., Chakraborty, S., Das, T., Venkatesh, M. and Ramamoorthy, N. (2003) Production Logistics of ${ }^{177}$ Lu for Radionuclide Therapy. Applied Radiation and Isotopes, 59, 109-118. http://dx.doi.org/10.1016/S0969-8043(03)00158-1

[37] Dadachova, E., Mirzadeh, S., Lambrecht, R.M., Hetherington, E.L. and Knapp Jr., F.F. (1994) Separation of Carrier-Free Holmium-166 from Neutron-Irradiated Dysprosium Targets. Analytical Chemistry, 66, 4272-4277. http://dx.doi.org/10.1021/ac00095a024

[38] Horwitz, E.P., Bloomquist, C.A.A. and Delphin, W.H. (1977) Radiochemical Separations by Liquid-Liquid Chromatography Using PSM Support. Journal of Chromatographic Science, 15, 41-46. http://dx.doi.org/10.1093/chromsci/15.2.41

[39] Horwitz, E.P. and Bloomquist, C.A.A. (1975) Chemical Separations for Super-Heavy Element Searches in Irradiated Uranium Targets. Journal of Inorganic and Nuclear Chemistry, 37, 425-434. http://dx.doi.org/10.1016/0022-1902(75)80350-2

[40] Schweitzer, G.K. and Pesterfield, L.L. (2010) The Aqueous Chemistry of the Elements. Oxford University Press, New York. 